\title{
Commentary: Porcine bioprosthetic root replacement for aortic stenosis: Farcical or sensible?
}

\author{
Faiza M. Khan, MD, Arash Salemi, MD, and T. Sloane Guy, MD
}

\author{
From the Department of Cardiothoracic Surgery, Weill Cornell Medicine, New York, NY. \\ Disclosures: T.S.G. is a consultant for Medtronic, Edwards Lifesciences; and Verb Surgical/Ethicon. All other \\ authors have nothing to disclose with regard to commercial support. \\ Received for publication Nov 19, 2018; accepted for publication Nov 19, 2018; available ahead of print Dec 28, \\ 2018. \\ Address for reprints. T. Sloane Guy, MD, Department of Cardiothoracic Surgery, Weill Cornell Medicine, \\ 525 E 68th St, New York, NY 10065 (E-mail: sloaneguy@gmail.com). \\ J Thorac Cardiovasc Surg 2019;158:1030-1 \\ $0022-5223 / \$ 36.00$ \\ Copyright (c) 2018 by The American Association for Thoracic Surgery \\ https://doi.org/10.1016/j.jtcvs.2018.11.065
}

In this issue of the Journal, Bianco and colleagues ${ }^{1}$ report retrospective data suggesting that aortic root replacement (ARR) with stentless porcine bioprostheses is perhaps a better option for surgical aortic valve replacement (SAVR) in patients with aortic stenosis in the absence of other indications for ARR. Advantages discussed include avoiding patient-prosthesis mismatch (PPM) with lower transvalvular gradients than after either SAVR or valve-in-valve transcatheter aortic valve replacement (TAVR) in redo operations. ${ }^{1}$ They report a 30 -day mortality of $7.1 \%$ in a relatively high-risk cohort of patients with a Society of Thoracic Surgeons predicted risk of mortality of $8.1 \%$. Many of these patients underwent redo operations, and several underwent concomitant procedures that precluded TAVR. Bianco and colleagues ${ }^{1}$ are to be commended on their outstanding outcomes.

In 1978, Rahimtoola ${ }^{2}$ described PPM as a less than ideal valve area after prosthetic implantation, leading to a gradient across ventricular outflow. This is important, because PPM correlates with poorer long-term outcomes. One could argue that in the current era of excellent TAVR results, there is no need to consider ARR in patients requiring isolated redo AVR after previous stented SAVR or ARR ( $21 \%$ of this study's cohort), particularly with a SAVR prosthesis of adequate size or with the ability to "crack" the SAVR prosthesis and place a larger TAVR device? In a recent series, Herrmann and colleagues ${ }^{3}$ reported rates of severe and moderate PPM as high as $12 \%$ and $25 \%$, respectively, after TAVR. In light of this, if PPM is to be expected after TAVR on the basis of preoperative characteristics, the approach of Bianco and colleagues ${ }^{1}$ seems valuable for patients. This may become more relevant as TAVR trials currently focus on low-risk patients. ${ }^{4}$

ARR by all surgeons as a means to justify lower transvalvular gradients across all patients, however, may be a "when all you have is a hammer then everything is a nail" approach. ARR is traditionally associated with increased mortality, coronary ischemic complications, and transfusions, and with longer crossclamp and

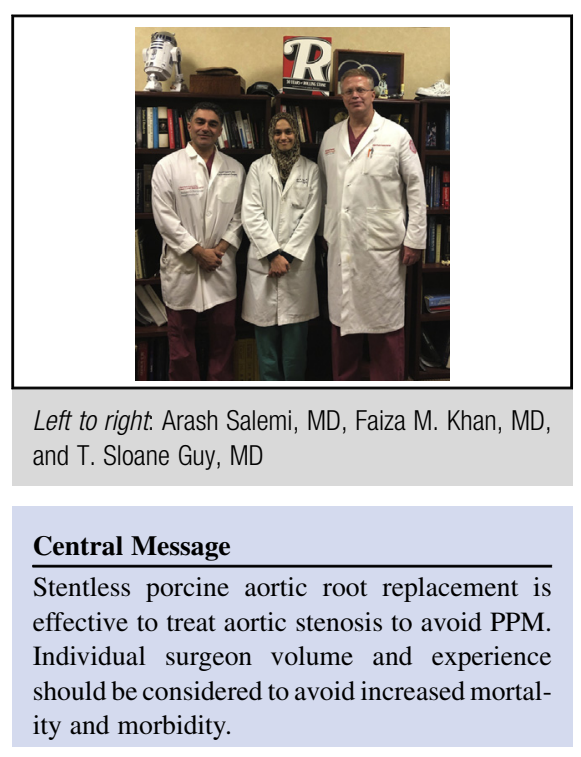

See Article page 1021.

cardiopulmonary bypass times. ${ }^{5}$ Although many highvolume surgical groups, ${ }^{6,7}$ such as that of Bianco and colleagues, ${ }^{1}$ have achieved outcomes with ARR similar to those with SAVR, this may not be for those who rarely perform ARR. Although some advantages of comparable durability have been seen between older stented bioprosthetic valves and stentless porcine valves, newer generation stented valves are purported to outlast the previously expected 10- to 15-year valve life. Furthermore, future valve-in-valve TAVR options for homograft or stentless porcine valves may be associated with higher rates of complications and lower rates of device success. $^{8}$

Aortic root enlargement procedures, including NicksNunez or Manouguian procedures, are as successful at tackling PPM. ${ }^{9}$ Many surgeons, however, are not facile with these techniques. Sutureless, rapid-deployment SAVR prostheses or stentless valves placed with inclusion techniques also may achieve low transvalvular gradients, and they represent another option for the patient with a small aortic annulus. In the hands of high-volume aortic surgeons, ARR results can mirror those of SAVR, as this group has demonstrated. Although we do suggest caution in using stentless porcine ARR instead of SAVR to avoid PPM routinely, particularly by surgeons with low-volume ARR experience, Bianco and colleagues ${ }^{1}$ have added an important implement to the surgeon's toolbelt. 


\section{References}

1. Bianco V, Kilic A, Gleason TG, Aranda-Michel E, Navid F, Mulukutla S, et al. Aortic root replacement with stentless xenografts in patients with aortic stenosis. J Thorac Cardiovasc Surg. 2019;158:1021-7.

2. Rahimtoola SH. The problem of valve prosthesis-patient mismatch. Circulation. 1978;58:20-4.

3. Herrmann HC, Daneshvar SA, Fonarow GC, Stebbins A, Vemulapalli S, Desai ND, et al. Prosthesis-patient mismatch in 62,125 patients following transcatheter aortic valve replacement: from the STS/ACC TVT Registry. J Am Coll Cardiol. 2018;72:2701-11.

4. ClinicalTrials.gov, US National Library of Medicine. The PARTNER 3 TrialThe Safety and Effectiveness of the SAPIEN 3 Transcatheter Heart Valve in Low Risk Patients With Aortic Stenosis (P3). Available at: https://clinicaltrials. gov/ct2/show/NCT02675114. Accessed December 18, 2018.

5. Brandt M, Abdelkerim S, Clemm S, Böning A, Cremer J. Composite valve graft versus separate aortic valve and ascending aortic replacement. Cardiology. 2004; 102:156-9.

6. Bach DS, Kon ND. Long-term clinical outcomes 15 years after aortic valve replacement with the Freestyle stentless aortic bioprosthesis. Ann Thorac Surg 2014;97:544-51.

7. David TE, Pollick C, Bos J. Aortic valve replacement with stentless porcine aortic bioprosthesis. J Thorac Cardiovasc Surg. 1990;99:113-8.

8. Duncan A, Davies S, Di Mario C, Moat N. Valve-in-valve transcatheter aortic valve implantation for failing surgical aortic stentless bioprosthetic valves: a single-center experience. J Thorac Cardiovasc Surg. 2015;150:91-8.

9. Castro LJ, Arcidi JM Jr, Fisher AL, Gaudiani VA. Routine enlargement of the small aortic root: a preventive strategy to minimize mismatch. Ann Thorac Surg. 2002; 74:31-6; discussion 36. 